\title{
Combined Tenodesis-Capsulodesis for Scapholunate Instability: Minimum 2-Year Follow-Up
}

\author{
Pablo De Carli, MD ${ }^{1} \quad$ Agustin G. Donndorff, MD ${ }^{1} \quad$ Miguel Tovar Torres, MD ${ }^{1} \quad$ Jorge G. Boretto, MD ${ }^{1}$ \\ Gerardo L. Gallucci, MD ${ }^{1}$ \\ ${ }^{1}$ Hospital Italiano de Buenos Aires, “Carlos E. Ottolenghi” Institute, \\ Hand Surgery and Upper Extremity Center, Buenos Aires, Argentina \\ J Wrist Surg 2017;6:11-21.

\begin{abstract}
Address for correspondence Pablo De Carli, MD, Hospital Italiano de Buenos Aires, "Carlos E. Ottolenghi” Institute, Hand Surgery and Upper Extremity Center, Gascón 450, CABA, C1199ACK Buenos Aires,
\end{abstract} \\ Argentina (e-mail: pablo.decarli@gmail.com).
}

\begin{abstract}
Keywords

- capsulodesis

- carpal instability

- scapholunate dissociation

- tenodesis

Background The aim of this study is to evaluate the clinical and radiological midterm results of a combined dorsal tenodesis-capsulodesis for static and reducible scapholunate dissociation (SLD).

Patients and Methods We evaluated 20 of 22 consecutive patients with static SLD minimum with follow-up of 2 years operated between 2003 and 2012. The mean age was 40 years (range: 23-65 years). Seventeen were men. Final evaluation included comparative wrist range of motion (ROM) and grip strength, pre- and postoperative pain and function by visual analog scale, and QuickDASH and Wrightington scores. Radiographs included preoperative, early postoperative, and final X-rays. Scapholunate space (SLS) and scapholunate and radioscaphoid angles (SLA and RSA) were measured. Statistical significance was evaluated with Student $t$-test, considered significant when $p<0.05$.

Results Mean follow-up was 67 months (range: $24-126$ months). Mean final ROM was: flexion 55 degrees (73\%), extension 62 degrees (90\%), radial deviation 19 degrees (82\%), and ulnar deviation 44 degrees (90\%). Mean grip strength was $44 \mathrm{~kg}(92 \%)$. Pain at rest improved from 3.4 to $0.5(p<0.05)$. Pain in activity improved from 7 to 1.7 $(p<0.05$ ). Final function was 8.5 (preoperative, 5.2; $p<0.05$ ). Mean QuickDASH score improved from 38 to $8(p<0.05)$. Functional Wrightington score was as follows: 13 excellent, 3 good, 1 regular, and 3 poor. There were three postoperative minor complications. Radiological results (preoperative/early postoperative/final follow-up) were as follows: SLS, 4.7/1.6/1.8 mm; and SLA, 60/50/62 degrees; RSA, 39/45/37 degrees. Four patients showed arthritic changes (two SLAC wrist).

Conclusion The clinical and radiological results with more than 2-year follow-up suggest that this technique may be effective, reproducible, and safe for symptomatic static and reducible SLD.

Level of Evidence Level IV, case series.
\end{abstract}

received

February 15, 2016

accepted

March 17, 2016

published online

May 9, 2016
Copyright ( 2017 by Thieme Medical Publishers, Inc., 333 Seventh Avenue, New York, NY 10001, USA. Tel: +1(212) 584-4662.
DOI http://dx.doi.org/ 10.1055/s-0036-1583304. ISSN 2163-3916. 
Scapholunate dissociation (SLD) is the most common cause of wrist instability and severe dysfunction of the wrist in young patients. $^{1}$

Numerous surgical strategies have been developed to address SLD. Many of these procedures may be grouped generically into bone and soft-tissue reconstructions. Unfortunately, so far no therapeutic alternatives have shown predictable long-term results in relieving the symptoms and preventing arthritic changes, especially in severe cases with a static instability. $^{2-9}$ Thus, there is still no consensus about what is the ideal management of this complex problem.

Previously, we described an alternative for scapholunate ligament reconstruction that combined a novel tenodesis using a strip of the extensor carpi radialis longus (ECRL) ${ }^{10}$ with a Mayo-type capsulodesis ${ }^{11}$ through a single dorsal approach without tunneling the scaphoid, with good preliminary results (-Figs. $\mathbf{1}$ and $\mathbf{2}$ ).

The aim of this study is to describe the midterm clinical and radiological results of this technique in cases with static reducible rotary subluxation of the scaphoid.

\section{Materials and Methods}

We performed a retrospective analysis of 28 consecutive patients operated in our institution for SLD between September 2003 and July 2015 with the combined ligament reconstruction technique. Only those cases with an isolated complete tear with static-reducible carpal instability and a nonrepairable ligament, without preconditions, and with a minimum follow-up of 2 years were included in this study. Patients presenting with other stages of scapholunate injury at the time of surgery, those with associated injuries, patients treated with another surgical technique, and those with less than 2 years' follow-up were excluded.

Of the original 22 cases who met the inclusion and exclusion criteria, 20 were available for follow-up examination at an average of 65 months postoperatively (range: 24-126 months). There were 17 men and 3 women, and the mean age was 40 years (range: $23-65$ years) at the time of surgery. The dominant hand was involved in 13 cases. The mean time from injury to operation was 9 months (range: 2-30 months). - Table 1 presents the demographic data for the entire group.

All patients were interviewed and examined by a single examiner not involved in the surgery. Objective clinical evaluation included range of flexion/extension and radial/ ulnar deviation measured with a goniometer and grip strength using a Jamar dynamometer. Unfortunately, we could not find full retrospective information of these parameters in all patients before surgery; this is why, they were not included in the final analysis. Pain and function were evaluated pre- and postoperatively using a visual analog scale (VAS). All patients completed the QuickDASH questionnaire. Furthermore, the specific function of the wrist was evaluated with the Wrightington Hospital wrist scoring system that includes both objective and subjective parameters: pain, function, motion, and grip strength. ${ }^{12,13}$ Questions about working and sports activity status, and satisfaction with the operation were also included.

Radiological analysis included preoperative, immediate postoperative, and final studies. This involved posteroanterior and lateral views, "forced closing fist" stress views (in 16/ 20 cases), and radioulnar deviation of both wrists. All measurements were performed digitally by two investigators using the RAIM viewer software. On the lateral radiographs, the scapholunate and radioscaphoid angles (SLA and RSA, respectively) were measured using the tangential and axial methods, respectively. ${ }^{14}$ The scapholunate space (SLS) was measured on posteroanterior and stress views (distance between midpoints of the edge of each bone).${ }^{15}$ The presence of osteoarthritic changes were also determined.

Statistical analysis of comparing clinical and radiologic parametric data was performed by the Student $t$-test. A $p$-value $<0.05$ was considered as significant.

\section{Results}

- Tables 2 and $\mathbf{3}$ described the objective and subjective results of the clinical evaluation. At the final follow-up examination,

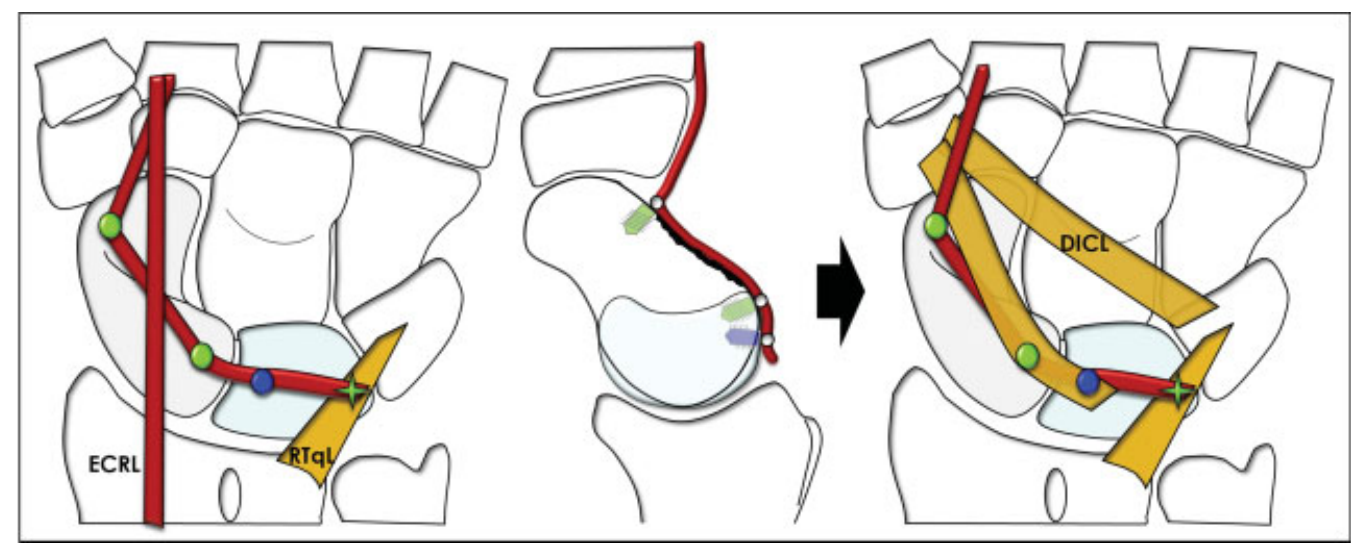

Fig. 1 Tenodesis using a distally based strip of the ECRL fixed with three suture anchors to the proximal and distal pole of the scaphoid and lunate. Reinforcement is made with a dorsal capsulodesis as described by Walsh et al. ${ }^{11}$ DICL, dorsal intercarpal ligament; RTqL, radiotriquetral ligament. 
the mean range of wrist motion relative to the contralateral side was: flexion $=73 \%$; extension $=90 \%$; radial deviation $=82 \%$; and ulnar deviation $=90 \%$. The final grip strength was $92 \%$, compared with the other side. Pain relief was statistically significant. At final evaluation, only two cases presented increase of pain at rest compared with preoperative values, and five cases referred increased pain during activities. The improvement of function was also statistically

A
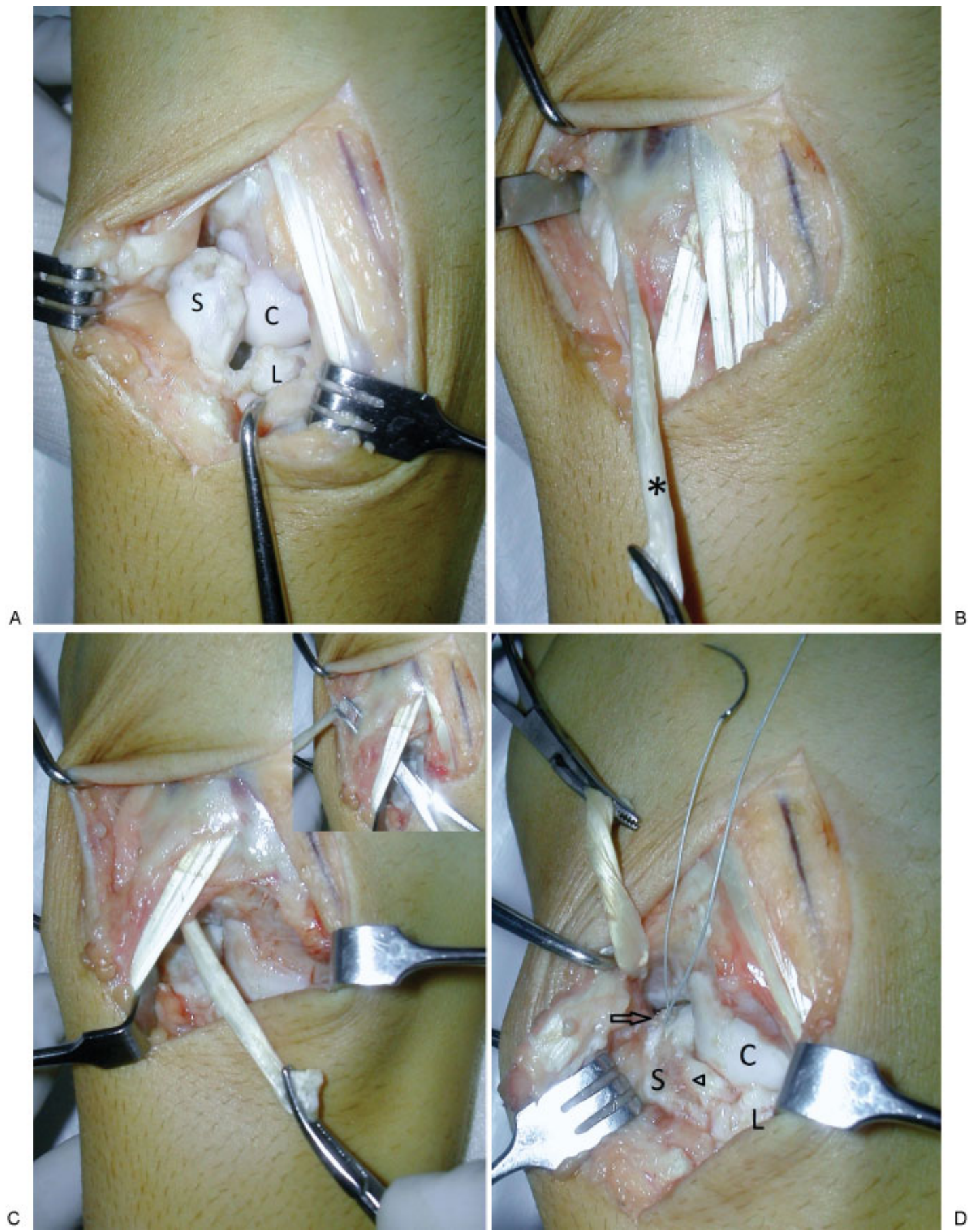

Fig. 2 A 30-year-old man with static SLD in his right dominant wrist (case 3). (A) Dorsal approach demonstrating a complete irreparable SL ligament tear with rotary subluxation of the scaphoid (S, scaphoid; C, capitate; L, lunate). (B) After carpal reduction, a distally based strip of the ECRL $\left({ }^{*}\right)$ is harvested through the same dorsal approach. (C) The ECRL strip is passed below the extensor carpi radialis brevis and extensor digitorum. (D) A channel is carved over the dorsal aspect of the scaphoid and lunate to uncover cancellous bone (arrowhead). At first, the tendon strip is fixed on the distal pole of the scaphoid with an anchor suture (arrow) to prevent rotary subluxation. (E) Subsequently, the strip is fixed on the proximal pole of the scaphoid and lunate with another two anchor sutures (arrows) to reconstruct the dorsal SL ligament. (F) Thereafter, the tendon is sutured onto the distal portion of the RTqL to preclude ulnar translation and extension of the lunate (arrow). Once the tendon reconstruction is finished, reinforcement is made with a Mayo dorsal capsulodesis using a proximal radially based slip of the dorsal intercarpal ligament $\left(^{*}\right)$. (G) Finally, the dorsal capsular flap (DC) is then brought back to its original position and sutured. 


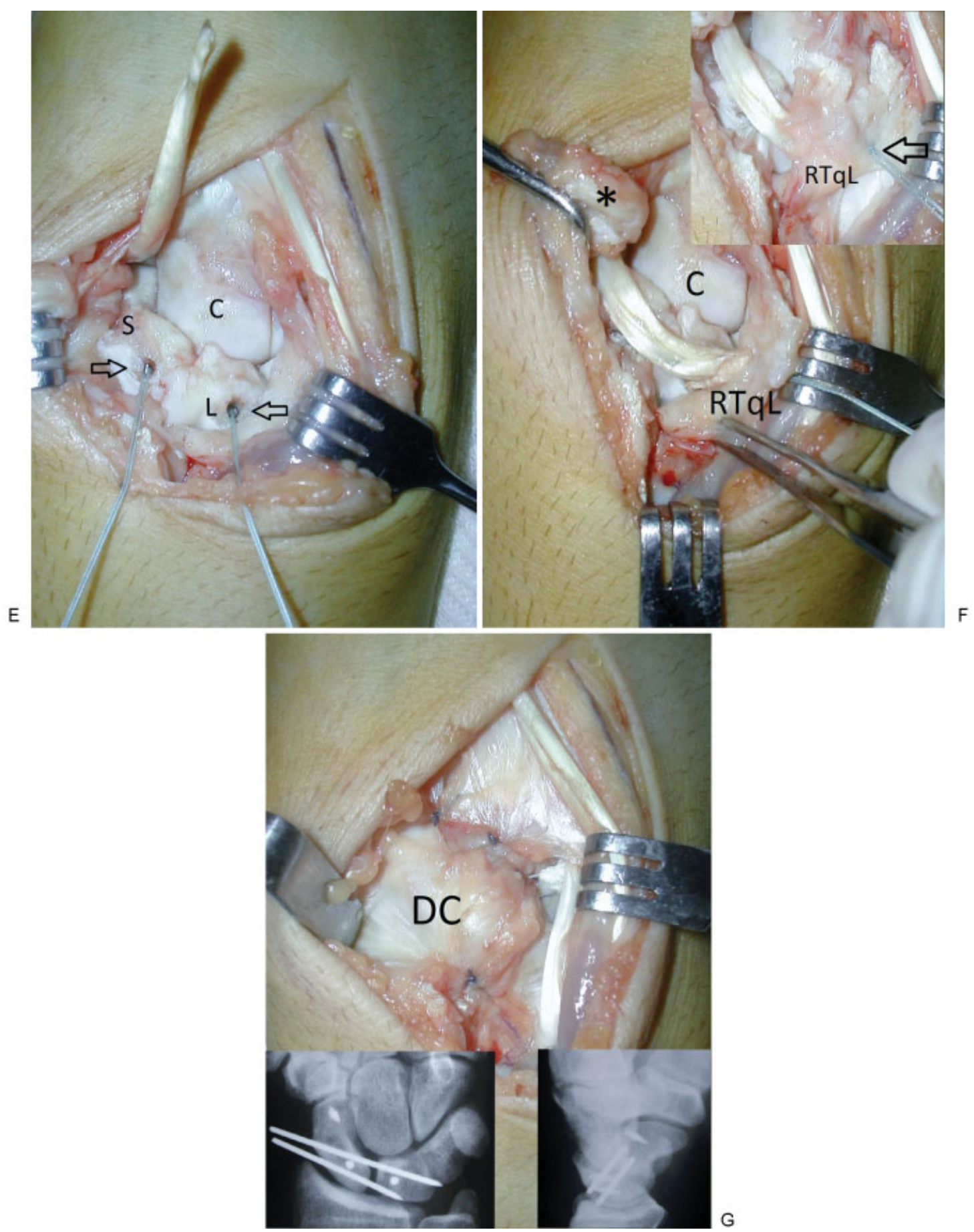

Fig. 2 (Continued)

significant. In 16 cases, the final postoperative function was superior to preoperative.

At final review, there was a significant decrease in the QuickDASH score, representing an improvement in the general function of the injured upper extremity. The functional results of the wrist according to the score of Wrightington were excellent in 13, good in 3, fair in 1, and poor in 3 cases. Before surgery, 11 patients reported a restricted work activity, while in the last assessment only 3 cases were restricted. Sports activity was restricted in 18 cases preoperatively and in 6 cases postoperatively. Fifteen patients (75\%) returned to their labor or sports activities prior to the injury. Finally, 11 patients were very satisfied with the result, 5 patients satisfied, 3 patients mildly satisfied, and 1 patient dissatisfied.

Radiological outcomes are summarized in - Table 4. - Fig. 3 shows the radiological results of an exemplifying case. When comparing the preoperative with the immediate postoperative findings, there were significant reductions in the three parameters evaluated. Both SLA and RSA increased significantly thereafter, while the SLS remained without significant changes. 
Table 1 Demographic data

\begin{tabular}{|l|l|l|l|l|l|}
\hline Patient & Gender & Age at surgery (y) & Injured limb/dominant limb & Delay for surgery (mo) & Follow-up (mo) \\
\hline 1 & $\mathrm{~F}$ & 43 & $\mathrm{~L} / \mathrm{R}$ & 15 & 126 \\
\hline 2 & $\mathrm{M}$ & 43 & $\mathrm{R} / \mathrm{R}$ & 6 & 108 \\
\hline 3 & $\mathrm{M}$ & 30 & $\mathrm{R} / \mathrm{R}$ & 6 & 105 \\
\hline 4 & $\mathrm{M}$ & 31 & $\mathrm{R} / \mathrm{R}$ & 30 & 106 \\
\hline 5 & $\mathrm{M}$ & 40 & $\mathrm{R} / \mathrm{L}$ & 12 & 93 \\
\hline 6 & $\mathrm{M}$ & 45 & $\mathrm{~L} / \mathrm{R}$ & 6 & 72 \\
\hline 7 & $\mathrm{M}$ & 32 & $\mathrm{~L} / \mathrm{L}$ & 8 & 87 \\
\hline 8 & $\mathrm{M}$ & 35 & $\mathrm{R} / \mathrm{R}$ & 10 & 29 \\
\hline 9 & $\mathrm{M}$ & 49 & $\mathrm{R} / \mathrm{R}$ & 91 \\
\hline 10 & $\mathrm{~F}$ & 36 & $\mathrm{R} / \mathrm{R}$ & 12 & 72 \\
\hline 11 & $\mathrm{M}$ & 48 & $\mathrm{R} / \mathrm{R}$ & 8 & 60 \\
\hline 12 & $\mathrm{M}$ & 30 & $\mathrm{R} / \mathrm{R}$ & 29 & 60 \\
\hline 13 & $\mathrm{M}$ & 39 & $\mathrm{R} / \mathrm{R}$ & 4 & 56 \\
\hline 14 & $\mathrm{M}$ & 48 & $\mathrm{~L} / \mathrm{R}$ & 6 & 50 \\
\hline 15 & $\mathrm{M}$ & 65 & $\mathrm{~L} / \mathrm{R}$ & 3 & 41 \\
\hline 16 & $\mathrm{M}$ & 48 & $\mathrm{R} / \mathrm{R}$ & 2 & 34 \\
\hline 17 & $\mathrm{M}$ & 34 & $\mathrm{R} / \mathrm{L}$ & 10 & 34 \\
\hline 18 & $\mathrm{M}$ & 23 & $\mathrm{R} / \mathrm{L}$ & 2 & 33 \\
\hline 19 & $\mathrm{~F}$ & 41 & $\mathrm{R} / \mathrm{R}$ & 2 & 24 \\
\hline 20 & $\mathrm{M}$ & 34 & $\mathrm{~L} / \mathrm{L}$ & 6 & 24 \\
\hline Mean & $17 \mathrm{M} / 3 \mathrm{~F}$ & 40 & & 3 & 65 \\
\hline
\end{tabular}

Analyzing the data individually, all but one patient had a loss of the initial reduction in any of the three parameters evaluated: SLS in 6 cases ( 11 cases on stress views); SLA in 16 cases; and RSA in 14 cases. However, only three patients had a carpal collapse (loss of all three parameters simultaneously). Finally, four cases showed arthritic changes. One of these cases evolved into an scapholunate advanced collapse (SLAC) II wrist and another into an SLAC III (-Fig. 4). Another case presented isolated advance midradiocarpal degenerative osteoarthritis but similar to the contralateral uninjured wrist (case 15, a man of 68 years at final evaluation). The last case showed osteoarthritis only in the midcarpal joint without significant widening of scapholunate gap, subluxation of the scaphoid, or carpal collapse (-Fig. 5).

There were three postoperative complications. One patient presented early migration of K-wires that did not seem to have affected the final outcome. Another two patients presented temporary radial sensory nerve dysesthesias that resolved spontaneously.

\section{Discussion}

The primary goals in the treatment of scapholunate instability are to relieve the patient's symptoms, thus preserving a functional wrist mobility, and to prevent carpal collapse, thereby avoiding osteoarthritic changes., ${ }^{76,17}$ A variety of surgical techniques have been proposed to treat this complex problem, yet disagreement remains with respect to the best management. ${ }^{16-32}$

As mentioned by Kitay and Wolfe, ${ }^{16}$ in the presence of a flexible deformity (dynamic instability) without osteoarthritis

Table 2 Final postoperative clinical results: objective parameters

\begin{tabular}{|l|l|l|l|l|}
\hline & Injured wrist & Uninjured wrist & $\begin{array}{l}\text { Percentage relative to the } \\
\text { contralateral side (\%) }\end{array}$ & $p$ \\
\hline Flexion (degree) & $55(44-62)$ & $75(55-90)$ & 73 & 0.00001 \\
\hline Extension (degree) & $62(38-75)$ & $68(41-80)$ & 90 & 0.0005 \\
\hline Radial deviation (degree) & $19(14-32)$ & $24(12-45)$ & 82 & 0.006 \\
\hline Ulnar deviation (degree) & $44(30-58)$ & $49(30-66)$ & 90 & 0.002 \\
\hline Grip strength $(\mathrm{kg})$ & $44(11-61)$ & $48(29-69)$ & 92 & 0.003 \\
\hline
\end{tabular}


Table 3 Clinical results: subjective parameters

\begin{tabular}{|l|l|l|l|l|l|l|l|l|}
\hline \multirow{2}{*}{ Case } & \multicolumn{2}{|l|}{ Pain-rest (VAS) } & \multicolumn{2}{l|}{ Pain-activity (VAS) } & \multicolumn{2}{l|}{ Function (VAS) } & \multicolumn{2}{l|}{ QuickDASH } \\
\cline { 2 - 9 } & Pre-op & Post-op & Pre-op & Post-op & Pre-op & Post-op & Pre-op & Post-op \\
\hline 1 & 4 & 0 & 6 & 0 & 5 & 8 & 28 & 2 \\
\hline 2 & 3 & 0 & 8 & 0 & 4 & 10 & 40 & 13 \\
\hline 3 & 1 & 0 & 6 & 3 & 3 & 8 & 64 & 9 \\
\hline 4 & 1 & 0 & 6 & 0 & 5 & 9 & 25 & 2 \\
\hline 5 & 0 & 0 & 7 & 0 & 5 & 10 & 20 & 0 \\
\hline 6 & 3 & 1 & 8 & 4 & 3 & 5 & 66 & 46 \\
\hline 7 & 2 & 3 & 6 & 3 & 8 & 6 & 2 & 0 \\
\hline 8 & 5 & 1 & 7 & 1 & 6 & 9 & 52 & 2 \\
\hline 9 & 6 & 1 & 9 & 1 & 4 & 9 & 66 & 18 \\
\hline 10 & 2 & 3 & 5 & 7 & 7 & 6 & 36 & 38 \\
\hline 11 & 4 & 1 & 8 & 1 & 4 & 9 & 46 & 2 \\
\hline 12 & 5 & 0 & 9 & 0 & 4 & 10 & 42 & 0 \\
\hline 13 & 3 & 0 & 7 & 5 & 5 & 8 & 20 & 2 \\
\hline 14 & 7 & 0 & 10 & 0 & 2 & 9 & 60 & 0 \\
\hline 15 & 8 & 0 & 8 & 2 & 4 & 8 & 84 & 14 \\
\hline 16 & 2 & 0 & 2 & 0 & 10 & 10 & 6 & 2 \\
\hline 17 & 2 & 0 & 6 & 1 & 7 & 8 & 30 & 7 \\
\hline 18 & 3 & 0 & 8 & 1 & 5 & 9 & 28 & 2 \\
\hline 19 & 5 & 0 & 5 & 0 & 5 & 10 & 34 & 0 \\
\hline 20 & 1 & 0 & 8 & 5 & 8 & 8 & 10 & 0 \\
\hline Mean & 3.4 & 0.5 & 7 & 1.7 & 5.2 & 8.5 & 38 & 8 \\
\hline Range & $0-8$ & $0-3$ & $5-10$ & $0-7$ & $3-10$ & $5-10$ & $0-84$ & $0-46$ \\
\hline$p$-Value & $<0.001$ & & $<0.001$ & & $<0.001$ & & $<0.001$ & \\
\hline
\end{tabular}

Abbreviation: VAS, visual analog scale.

some type of soft-tissue reconstruction may be indicated. The majority of the capsulodesis bring good results in these cases. $^{13,22,33-36}$ However, long-term studies described severe deterioration of these results in cases with static instability. ${ }^{2,3,8}$

In an attempt to achieve a stronger reconstruction, numerous authors propose the utilization of some type of tenodesis. The short-term results using the different modern techniques show good clinical and radiological results. ${ }^{4,7}$ However, so far we have not found evidence in the literature that describes the evolution of these results in the medium- to long-term follow-up.

Preliminary results of our technique of combined dorsal tenodesis and capsulodesis with 2 years of mean follow-up were similar to the other alternatives. ${ }^{10}$ In this study, the results in the medium to long term were presented to determine whether they are maintained over time. According to the results obtained after an average 6-year follow-up, 16/ 20 patients were satisfied with the result, returning 15 of them to all their previous work and sports activities. No patient referred moderate or severe pain at rest (VAS [visual analog scale] $>4$ ), and only four patients presented moder- ate or severe pain during activity. Two of them were those with an SLAC wrist. In the other two cases, the pain was probably related to his activities (golf and graphic design), as radiologically they did not have evidence of a severe carpal collapse.

This new tenodesis using an ECRL tendon slip gives some advantages over other techniques described previously: (1) only one dorsal approach is required; (2) scaphoid tunneling is not necessary, and thus it is technically less demanding and avoids the potential risk of fracture or necrosis of the bone; and (3) it is possible to combine the tenodesis with a dorsal capsulodesis to achieve a more consistent reconstruction through a single dorsal approach without increasing morbidity and complexity of the procedure.

In relation to the radiological findings, there are no reports of any surgical interventions for this problem that demonstrate consistent results to prevent or delay the progression to an SLAC wrist. ${ }^{8,16}$ The correction and maintenance of alignment (kinetic) and mobility (kinematic) of the carpus are particularly relevant considering that many of these patients are young active people. As with all techniques of ligament 
Table 4 Radiological results

\begin{tabular}{|c|c|c|c|c|c|c|c|c|c|c|}
\hline \multirow[t]{2}{*}{ Case } & \multicolumn{4}{|c|}{ SLS (mm) } & \multicolumn{3}{|c|}{ SLA (degree) } & \multicolumn{3}{|c|}{ RSA (degree) } \\
\hline & Pre-op & $\begin{array}{l}\text { Immediate } \\
\text { post-op }\end{array}$ & $\begin{array}{l}\text { Final } \\
\text { post-op }\end{array}$ & $\begin{array}{l}\text { "Forced } \\
\text { closing fist" }\end{array}$ & Pre-op & $\begin{array}{l}\text { Immediate } \\
\text { post-op }\end{array}$ & $\begin{array}{l}\text { Final } \\
\text { post-op }\end{array}$ & Pre-op & $\begin{array}{l}\text { Immediate } \\
\text { post-op }\end{array}$ & $\begin{array}{l}\text { Final } \\
\text { post-op }\end{array}$ \\
\hline 1 & 4 & 2 & 2 & - & 52 & 28 & 29 & 40 & 46 & 42 \\
\hline 2 & 5.4 & 1.5 & 1.6 & - & 58 & 52 & 53 & 44 & 44 & 42 \\
\hline 3 & 6.3 & 1.8 & 1.9 & 2 & 70 & 65 & 72 & 41 & 48 & 24 \\
\hline 4 & 8.1 & 1.3 & 1.4 & - & 55 & 50 & 50 & 35 & 40 & 38 \\
\hline 5 & 6.3 & 1.8 & 1.9 & 2 & 70 & 23 & 54 & 31 & 62 & 39 \\
\hline 6 & 6.8 & 1.4 & 1.8 & 2.2 & 60 & 56 & 57 & 38 & 44 & 41 \\
\hline 7 & 7.6 & 1.4 & 1.6 & 2.9 & 86 & 86 & 92 & 36 & 36 & 30 \\
\hline 8 & 7.2 & 1.8 & 1.8 & 2.7 & 54 & 55 & 65 & 48 & 50 & 38 \\
\hline 9 & 1.8 & 1.7 & 1.7 & 2.9 & 45 & 45 & 54 & 46 & 48 & 40 \\
\hline 10 & 6.3 & 1.8 & 2.2 & 2.3 & 82 & 22 & 70 & 34 & 76 & 27 \\
\hline 11 & 3.6 & 2.7 & 2.7 & - & 60 & 55 & 67 & 35 & 40 & 37 \\
\hline 12 & 6.3 & 1 & 1 & 1.1 & 50 & 47 & 53 & 42 & 44 & 28 \\
\hline 13 & 6.2 & 0.9 & 0.9 & 0.9 & 58 & 54 & 70 & 34 & 38 & 30 \\
\hline 14 & 1.8 & 1.8 & 2.2 & 2.8 & 60 & 48 & 72 & 32 & 39 & 36 \\
\hline 15 & 3.6 & 1.8 & 2 & 3.6 & 87 & 60 & 63 & 28 & 30 & 29 \\
\hline 16 & 2.7 & 1.6 & 1.6 & 2 & 62 & 56 & 89 & 30 & 34 & 31 \\
\hline 17 & 4.6 & 1.1 & 1.1 & 1.2 & 45 & 45 & 54 & 40 & 42 & 40 \\
\hline 18 & 0.9 & 1 & 1.2 & 1.9 & 54 & 53 & 70 & 38 & 40 & 38 \\
\hline 19 & 2.7 & 2 & 4.5 & 4.5 & 52 & 46 & 49 & 50 & 55 & 55 \\
\hline 20 & 1.8 & 1.3 & 1.4 & 1.8 & 48 & 45 & 66 & 48 & 53 & 48 \\
\hline Mean & 4.7 & 1.6 & 1.8 & 2.3 & 60 & 50 & 62 & 39 & 45 & 37 \\
\hline Range & $0.9-8.1$ & $0.9-2.7$ & $0.9-4.5$ & $0.9-4.5$ & $45-87$ & $22-86$ & $29-92$ & $28-50$ & $30-76$ & $27-55$ \\
\hline$p$-Value & & $<0.001$ & 0.12 & & 0.007 & 0.003 & & 0.008 & 0.002 & \\
\hline
\end{tabular}

Abbreviations: RSA, radioscaphoid angle; SLA, scapholunate angle; SLS, scapholunate space.

reconstruction, it is expected that some radiological deterioration occurs over time. In our series, the SLS remained without significant changes over time. Technically, to avoid rotatory subluxation of the scaphoid, we believe it is critical to set the first anchor radially to the distal pole of the scaphoid to control not only flexion but also pronation of the carpal bone. On the contrary, the loss of the initial reduction was significant in the SLA and RSA, demonstrating a major difficulty of the procedure to support the alignment of the scaphoid and lunate in the sagittal plane. Nevertheless, at the time of the final evaluation, only four patients (20\%) presented carpal osteoarthritis. This percentage is similar to that presented by Garcia-Elias et al using the three-ligament reconstruction with a shorter follow-up, ${ }^{7}$ and lower than in previous studies using several capsulodesis with a long-term follow-up (27$50 \%) .^{2,3,8}$ Further evaluation of our patients will reveal whether these osteoarthritic changes will be maintained over time.
An alternative to soft-tissue reconstruction techniques is to conduct some type of limited carpal arthrodesis. The results reported are very similar to the ligament reconstructions but with higher incidence of complications, including nonunion and radiocarpal arthrosis (4-51\% and $15-35 \%$, respectively). ${ }^{21,37-40}$ The major advantage of dorsal capsulodesis and tenodesis when compared with partial arthrodesis is the preservation of some intercarpal motion. To achieve this, the reconstruction should be strong enough to stabilize the carpus, and simultaneously flexible enough to preserve its dynamics. To evaluate both features, we considered not only static radiographs, but also dynamic radiographs in maximum radioulnar deviation. Two-thirds of the cases examined showed some kind of mobility for flexion and extension of the scaphoid, suggesting the possibility of preserving at least part of the carpal biomechanics with this type of soft-tissue reconstruction (-Fig. 6). 
Regarding the level of evidence, this study presents all limitations associated with a case series retrospectively evaluated with no comparison group. In addition, the relatively small sample size determines some statistical limitations. However, some aspect must be considered to provide relevance to our results. While the technique presented would be also indicated in cases of SLD with dynamic instability (grade III of Garcia-Elias et al classification), in this study we decided to include only those with static reducible instability (grade IV), in which the prognosis is less predictable and therapeutic alternatives are more limited.
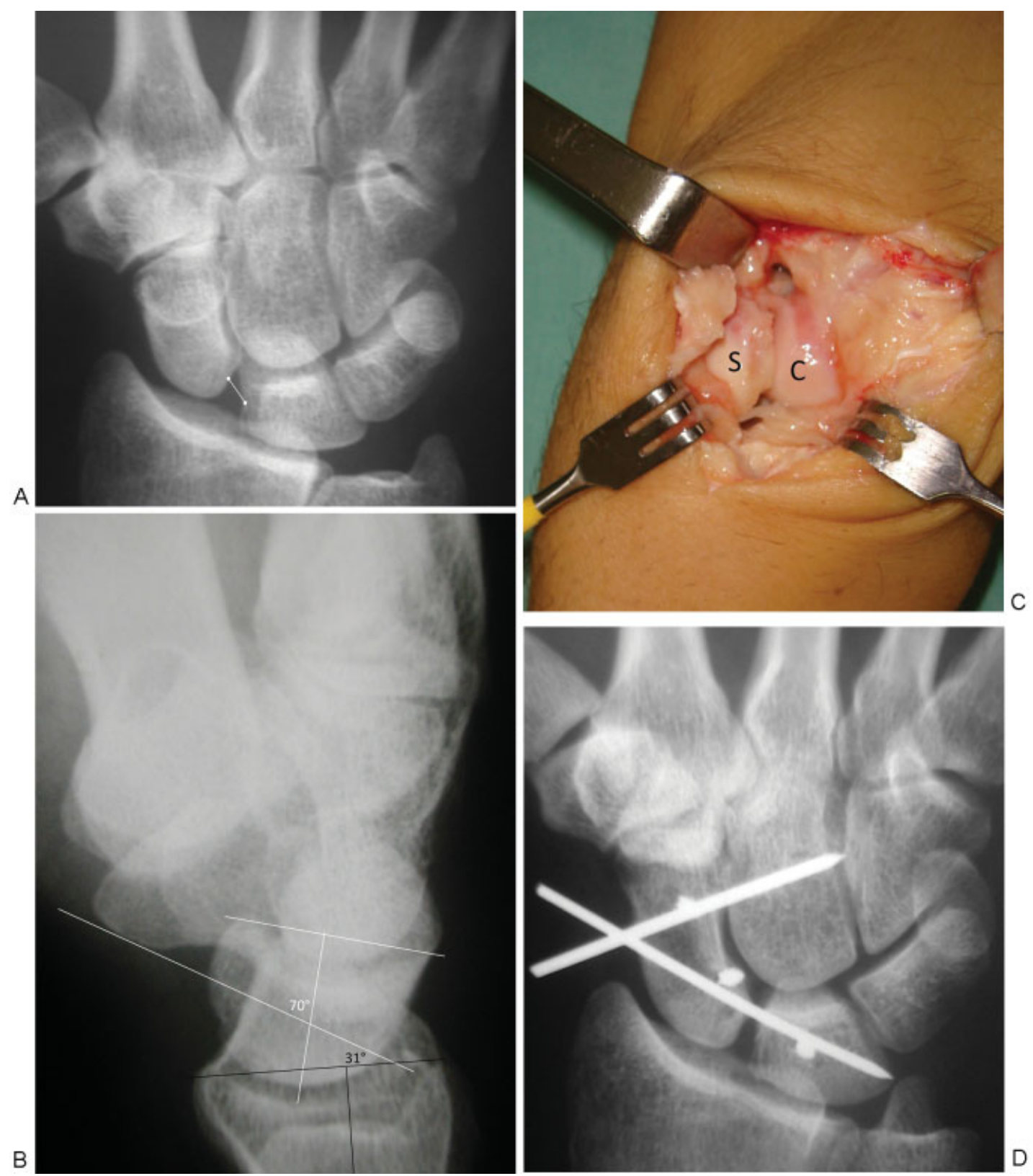

In conclusion, we believe that the results obtained justify the indication of this procedure in symptomatic patients, preserving in most cases pain relief and functional mobility of the wrist with acceptable radiographic changes for at least 5 years after average follow-up. However, re-evaluation of this result with a longer follow-up would be necessary in an attempt to determine its effectiveness in preventing or at least delaying the carpal collapse and osteoarthritic changes of the injured wrist, and also to define the surgical indication for asymptomatic patients.

Fig. 3 A 40-year-old man with static SLD in his right nondominant wrist (case 5). (A, B) Preoperative X-rays: SLS, 6.3 mm; SLA, 70 degrees; RSA, 31 degrees. (C) Intraoperative findings: total and irreparable ligament rupture with rotary subluxation of the scaphoid. (D, E) Immediate postoperative radiographs. Note some initial overcorrection. SLS, $1.8 \mathrm{~mm}$; SLA, 23 degrees; RSA, 62 degrees. (F, G) Comparative X-rays at final assessment (93 months) appreciating an acceptable carpal alignment. SLS, 1.9 mm; SLA, 54 degrees; RSA, 39 degrees. (H, I) Comparative "forced closing fist" stress views. The scapholunate space is maintained. 

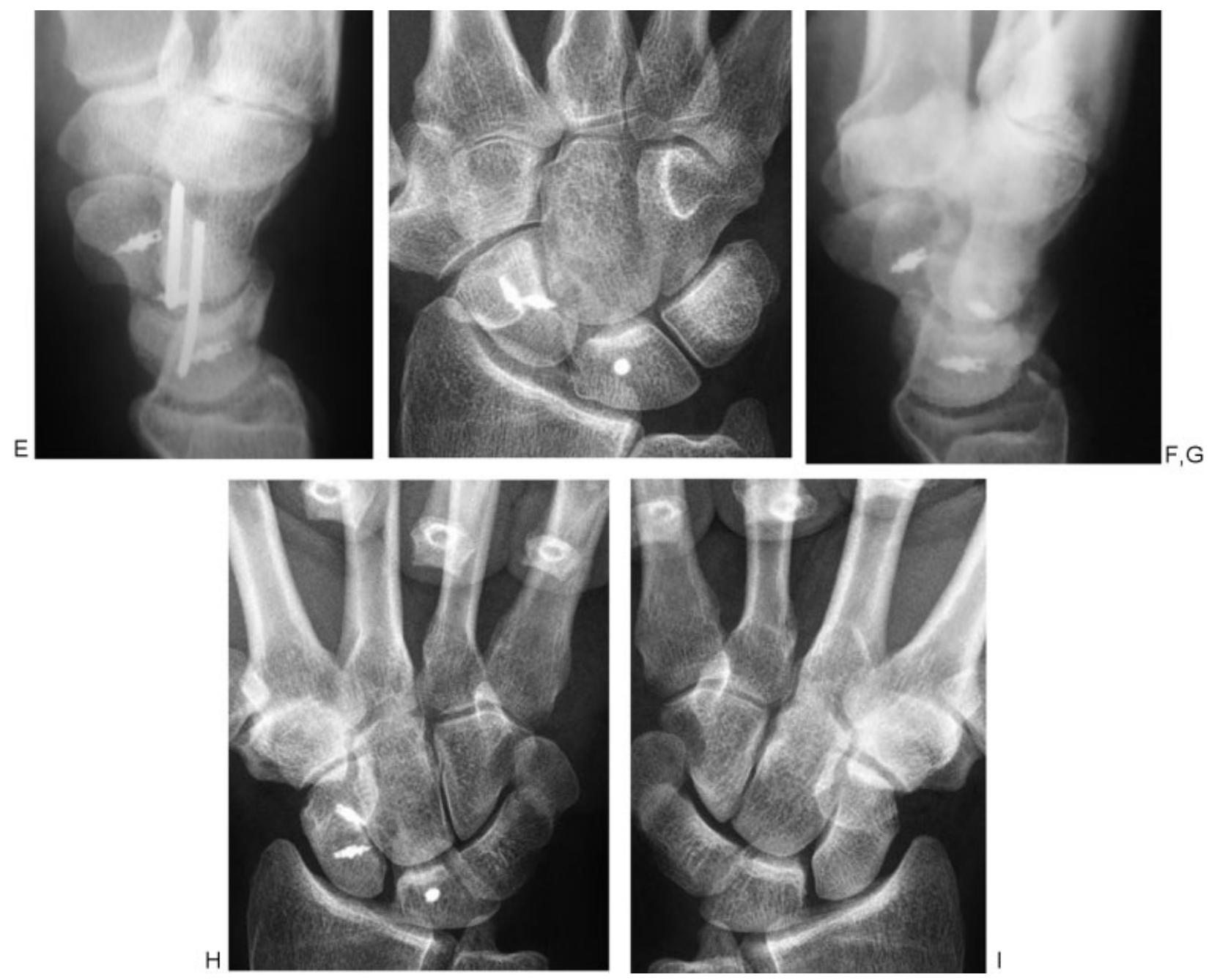

Fig. 3 (Continued)

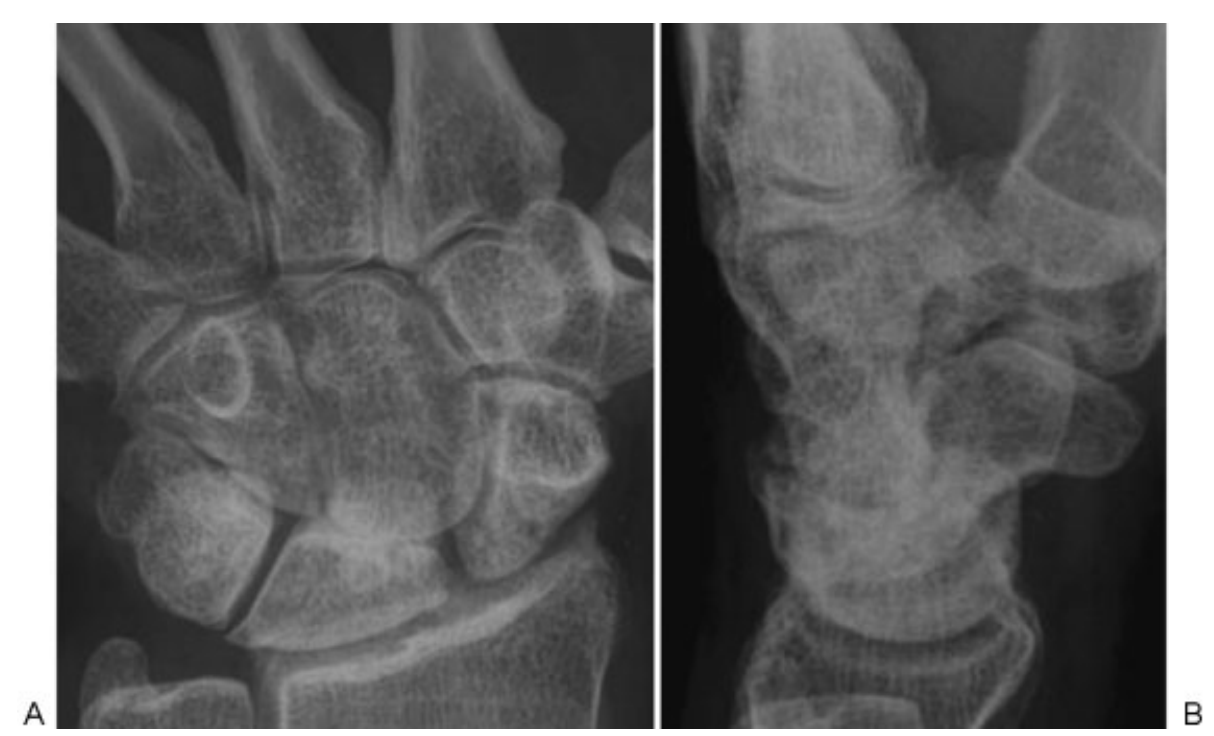

Fig. 4 Case 10. A 36-year-old woman presenting an SLAC III right wrist at final evaluation (72 months). (A, B) SLS, 2.3 mm; SLA, 70 degrees; RSA, 27 degrees. 


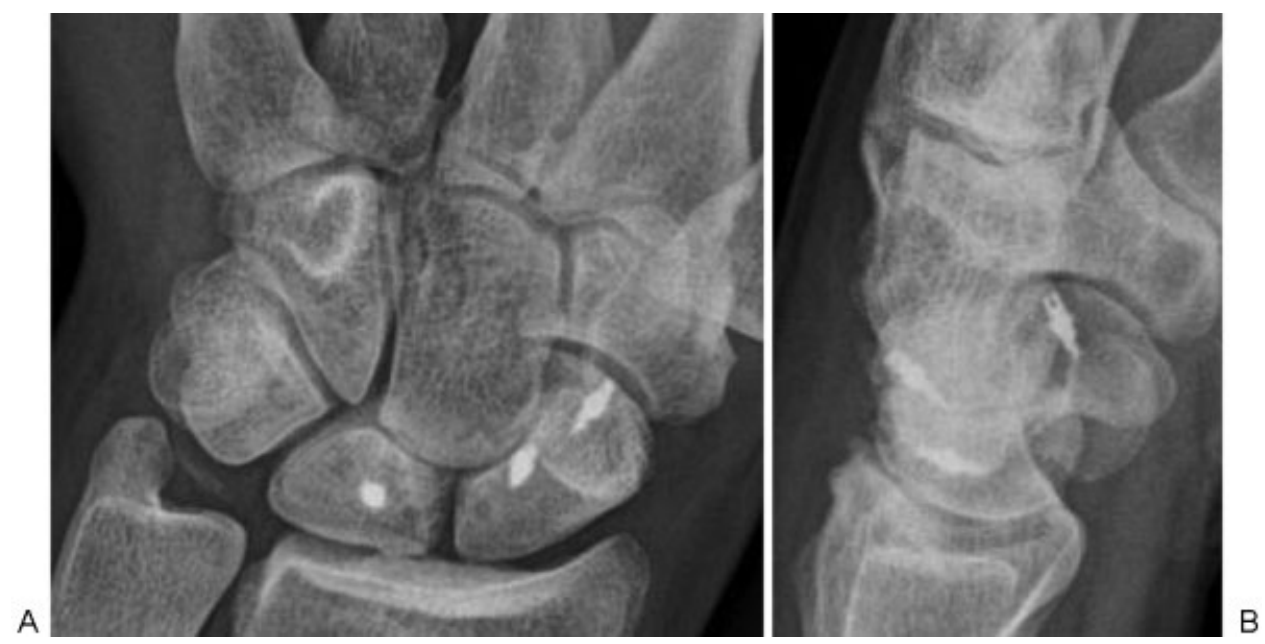

Fig. 5 Case 3. Patient with isolated midcarpal arthritis at final follow-up (105 months). (A, B) Nevertheless, X-rays demonstrate acceptable carpal alignment. SLS, 1,9 mm; SLA, 72 degrees; RSA, 24 degrees.

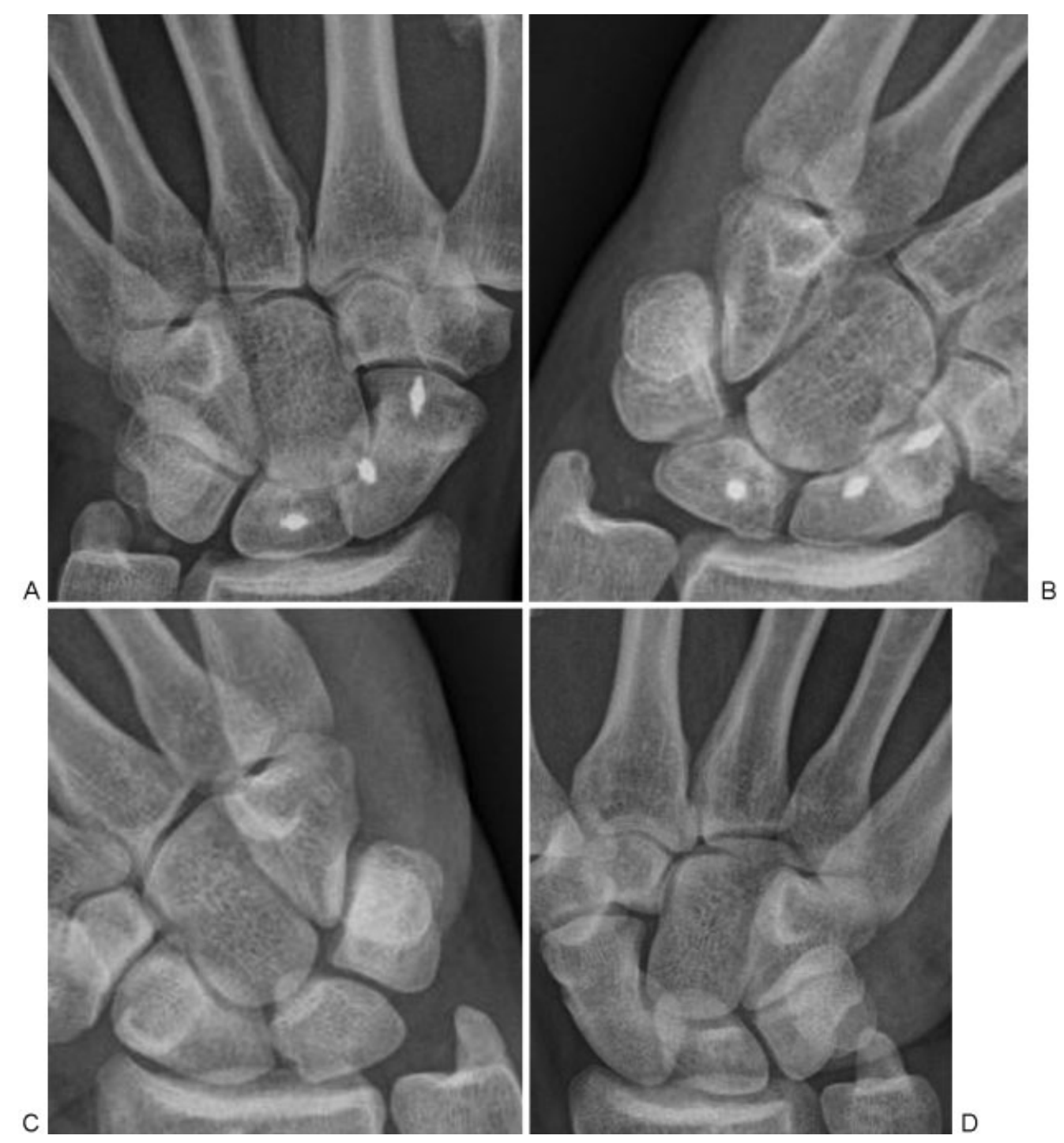

Fig. 6 Case 3. (A-D) Comparative radiographs in maximum radioulnar deviation of both wrists, showing certain mobility of the proximal carpal row (flexion-extension). 


\section{Note}

All authors adhere to the ethical standards described by the Committee on Publication Ethics and the International Committee of Medical Journal Editors.

\section{Conflict of Interest}

None.

\section{References}

1 Gelberman RH, Cooney WP III, Szabo RM. Carpal instability. J Bone Joint Surg Am 2000;82:578-594

2 Megerle K, Bertel D, Germann G, Lehnhardt M, Hellmich S. Longterm results of dorsal intercarpal ligament capsulodesis for the treatment of chronic scapholunate instability. J Bone Joint Surg Br 2012;94(12):1660-1665

3 Schweizer A, Steiger R. Long-term results after repair and augmentation ntercarpalsty of rotatory subluxation of the scaphoid. J Hand Surg Am 2002;27(4):674-684

4 Brunelli GA, Brunelli GR. A new technique to correct carpal instability with scaphoid rotary subluxation: a preliminary report. J Hand Surg Am 1995;20(3, Pt 2):S82-S85

5 Van Den Abbeele KL, Loh YC, Stanley JK, Trail IA. Early results of a modified Brunelli procedure for scapholunate instability. J Hand Surg [Br] 1998;23(2):258-261

6 Talwalkar SC, Edwards AT, Hayton MJ, Stilwell JH, Trail IA, Stanley JK. Results of tri-ligament tenodesis: a modified Brunelli procedure in the management of scapholunate instability. J Hand Surg [Br] 2006;31(1):110-117

7 Garcia-Elias M, Lluch AL, Stanley JK. Three-ligament tenodesis for the treatment of scapholunate dissociation: indications and surgical technique. J Hand Surg Am 2006;31(1):125-134

8 Gajendran VK, Peterson B, Slater RR Jr, Szabo RM. Long-term outcomes of dorsal intercarpal ligament capsulodesis for chronic scapholunate dissociation. J Hand Surg Am 2007;32(9):1323-1333

9 Chabas JF, Gay A, Valenti D, Guinard D, Legre R. Results of the modified Brunelli tenodesis for treatment of scapholunate instability: a retrospective study of 19 patients. J Hand Surg Am 2008; 33(9):1469-1477

10 De Carli P, Donndorff AG, Gallucci GL, Boretto JG, Alfie VA. Chronic scapholunate dissociation: ligament reconstruction combining a new extensor carpi radialis longus tenodesis and a dorsal intercarpal ligament capsulodesis. Tech Hand Up Extrem Surg 2011;15(1):6-11

11 Walsh JJ, Berger RA, Cooney WP. Current status of scapholunate interosseous ligament injuries. J Am Acad Orthop Surg 2002; 10(1):32-42

12 Cooney WP. Open reduction of distal radius fractures: indications, classifications and functional assessment. In: Cooney WP, Saffar P, eds. Fractures of the Distal Radius. London: Martin Dunitz; 1995: 118-125

13 Moran SL, Cooney WP, Berger RA, Strickland J. Capsulodesis for the treatment of chronic scapholunate instability. J Hand Surg Am 2005;30(1):16-23

14 Larsen CF, Mathiesen FK, Lindequist S. Measurements of carpal bone angles on lateral wrist radiographs. J Hand Surg Am 1991; 16(5):888-893

15 Lawand A, Foulkes GD. The "clenched pencil" view: a modified clenched fist scapholunate stress view. J Hand Surg Am 2003; 28(3):414-418, discussion 419-420

16 Kitay A, Wolfe SW. Scapholunate instability: current concepts in diagnosis and management. J Hand Surg Am 2012;37(10):2175-2196

17 Moran SL, Ford KS, Wulf CA, Cooney WP. Outcomes of dorsal capsulodesis and tenodesis for treatment of scapholunate instability. J Hand Surg Am 2006;31(9):1438-1446
18 Watson HK, Ryu J, Akelman E. Limited triscaphoid intercarpal arthrodesis for rotatory subluxation of the scaphoid. J Bone Joint Surg Am 1986;68(3):345-349

19 Blatt G. Capsulodesis in reconstructive hand surgery. Dorsal capsulodesis for the unstable scaphoid and volar capsulodesis following excision of the distal ulna. Hand Clin 1987;3(1):81-102

20 Almquist EE, Bach AW, Sack JT, Fuhs SE, Newman DM. Four-bone ligament reconstruction for treatment of chronic complete scapholunate separation. J Hand Surg Am 1991;16(2):322-327

21 Pisano SM, Peimer CA, Wheeler DR, Sherwin F. Scaphocapitate intercarpal arthrodesis. J Hand Surg Am 1991;16(2):328-333

22 Lavernia CJ, Cohen MS, Taleisnik J. Treatment of scapholunate dissociation by ligamentous repair and capsulodesis. J Hand Surg Am 1992;17(2):354-359

23 Linscheid RL, Dobyns JH. Treatment of scapholunate dissociation. Rotatory subluxation of the scaphoid. Hand Clin 1992;8(4):645-652

24 Rotman MB, Manske PR, Pruitt DL, Szerzinski J. Scaphocapitolunate arthrodesis. J Hand Surg Am 1993;18(1):26-33

25 Herbert TJ, Hargreaves IC, Clarke AM. A new surgical technique for treating rotary instability of the scaphoid. Hand Surg 1996;1:75-77

26 Slater RR Jr, Szabo RM. Scapholunate dissociation: treatment with the dorsal intercarpal ligament capsulodesis. Tech Hand Up Extrem Surg 1999;3(4):222-228

27 Rosenwasser MP, Miyasajsa KC, Strauch RJ. The RASL procedure: reduction and association of the scaphoid and lunate using the Herbert screw. Tech Hand Up Extrem Surg 1997;1(4):263-272

28 Wolf JM, Weiss AP. Bone-retinaculum-bone reconstruction of scapholunate ligament injuries. Orthop Clin North Am 2001; 32(2):241-246, viii

29 Seradge H, Baer C, Dalsimer D, Seradge A, Shafi RA, Parker W. Treatment of dynamic scaphoid instability. J Trauma 2004;56(6): 1253-1260

30 Zarkadas PC, Gropper PT, White NJ, Perey BH. A survey of the surgical management of acute and chronic scapholunate instability. J Hand Surg Am 2004;29(5):848-857

31 Bleuler P, Shafighi M, Donati OF, Gurunluoglu R, Constantinescu MA. Dynamic repair of scapholunate dissociation with dorsal extensor carpi radialis longus tenodesis. J Hand Surg Am 2008; 33(2):281-284

32 Binder AC, Kerfant N, Wahegaonkar AL, Tandara AA, Mathoulin CL. Dorsal wrist capsular tears in association with scapholunate instability: results of an arthroscopic dorsal capsuloplasty. J Wrist Surg 2013;2(2):160-167

33 Wintman BI, Gelberman RH, Katz JN. Dynamic scapholunate instability: results of operative treatment with dorsal capsulodesis. J Hand Surg Am 1995;20(6):971-979

34 Deshmukh SC, Givissis P, Belloso D, Stanley JK, Trail IA. Blatt's capsulodesis for chronic scapholunate dissociation. J Hand Surg [Br] 1999;24(2):215-220

35 Pomerance J. Outcome after repair of the scapholunate interosseous ligament and dorsal capsulodesis for dynamic scapholunate instability due to trauma. J Hand Surg Am 2006;31(8):1380-1386

36 Luchetti R, Atzei A, Cozzolino R, Fairplay T. Current role of open reconstruction of the scapholunate ligament. J Wrist Surg 2013; 2(2):116-125

37 Fortin PT, Louis DS. Long-term follow-up of scaphoid-trapeziumtrapezoid arthrodesis. J Hand Surg Am 1993;18(4):675-681

38 Chantelot C, Becquet E, Leconte F, Lahoude-Chantelot S, Prodomme G, Fontaine C. Scaphocapitate arthrodesis for chronic scapholunate instability: a retrospective study of 13 cases [in French]. Chir Main 2005;24(2):79-83

39 Delétang F, Segret J, Dap F, Dautel G. Chronic scapholunate instability treated by scaphocapitate fusion: a midterm outcome perspective. Orthop Traumatol Surg Res 2011;97(2):164-171

40 Luegmair M, Saffar P. Scaphocapitate arthrodesis for treatment of scapholunate instability in manual workers. J Hand Surg Am 2013; 38(5):878-886 